\title{
Macrophage-Derived Heme-Oxygenase-1: Expression, Regulation, and Possible Functions in Skin Repair
}

\author{
Heiko Kämpfer, Nicole Kolb, Markus Manderscheid, Christian Wetzler, Josef Pfeilschifter, \\ and Stefan Frank
}

Pharmazentrum Frankfurt, Klinikum der Johann Wolfgang Goethe-Universität, Frankfurt am Main, Germany

Accepted February 20, 2001

\begin{abstract}
Background: Expression and enzymatic activity of heme oxygenase (HO) has been implicated in the development, as well as in the resolution, of inflammatory conditions. Because inflammation is central to tissue repair, we investigated the presence and potential functions of $\mathrm{HO}$ in an excisional model of normal and diabetes-impaired wound repair in mice.

Materials and Methods: Expression of HO- $\mathrm{l}$ during cutaneous healing was analyzed by RNase protection assay, Western blot, and immunohistochemical techniques in a murine model of excisional repair. Furthermore, we determined HO-1-dependent release of proinflammatory cytokines from RAW 264.7 macrophages by enzyme-linked immunosorbent assay (ELISA).

Results: Upon injury, we observed a rapid and strong increase in HO-l mRNA and protein levels at the wound site. By contrast to normal repair, late stages of diabetesimpaired repair were associated with elevated $\mathrm{HO}-1$ expression. Besides a few keratinocytes of the hyperpro-
\end{abstract}

liferative epithelium, immunohistochemistry revealed infiltrating macrophages as the predominant and major source of HO-l at the wound site. In vitro studies demonstrated the potency of exogenous and also endogenous nitric oxide (NO) to strongly induce $\mathrm{HO}-1$ expression in RAW 264.7 macrophages. However, L-NIL-mediated enzymatic inhibition of inducible NO-synthase (iNOS) at the wound site in vivo was not paralleled by decreased HO-1 levels. In vitro inhibition of HO-1 enzymatic activity by tin protoporphyrin IX (SnPPIX) in RAW 264.7 macrophages markedly attenuated tumor necrosis factor- $\alpha$ (TNF- $\alpha$ ), but strongly increased interleukin-1 $\beta$ (IL-1 $\beta$ ) release in RAW 264.7 macrophages in vitro.

Conclusions: The observed injury-mediated increase in HO-l mRNA and protein at the wound site was due to infiltrating HO-1 expressing monocytic cells. Macrophagederived HO- 1 expression was not under regulatory control by $\mathrm{NO}$ in skin repair. We provide evidence that $\mathrm{HO}-1$ might exert a regulatory role in macrophage-derived cytokine release.

\section{Introduction}

Cutaneous wound healing represents a special situation to the body, as an injury of body surfaces more or less interferes with normal skin integrity that usually provides protection against different environmental conditions. Thus, a highly controlled mechanism of tissue repair has evolved that rapidly covers the area of injury and finally leads to formation of new skin tissue. Skin repair comprises tissue movements such as hemostasis, inflammation, granulation tissue formation, and re-epithelialization. These phases of tissue repair are well known to overlap in a temporal and spatial manner (1). However, the inflammatory phase of repair, initiated a few hours after injury by infiltration of immune cells from the vasculature, is of central importance for wound closure. If the wound site remains mainly

Address correspondence and reprint requests to: Dr. Stefan Frank, Pharmazentrum Frankfurt, Institut für Allgemeine Pharmakologie und Toxikologie, Klinikum der JWG-Universität Frankfurt/Main, Theodor-Stern-Kai 7, D-60590 Frankfurt/Main, Germany. Phone: 069-6301-6954; Fax: 069-6301-7942;

e-mail: S.Frank@em.uni-frankfurt.de uncontaminated, the initial neutrophil-dominated inflammatory phase rapidly proceeds toward macrophage-driven wound inflammation $(1,2)$. As demonstrated in a classical experimental setup by Leibovich and Ross (3), the wound macrophage crucially contributes to tissue repair, as depletion of monocytic phagocytes from the wound site resulted in a dramatic impairment of the wound healing process. The macrophage is now well established as an important source of growth factors and cytokines triggering fibroblast and endothelial cell proliferation $(1,4)$. Accordingly, macrophage action during repair combines both inflammation and granulation tissue formation by interconnecting both processes into an indistinguishable unit.

Nevertheless, inflammation has to be tightly controlled, because a prolonged or excessive inflammatory phase results in tissue injury or tissue damage. Recent studies have evidenced a participation of heme oxygenase $(\mathrm{HO})$ in progression and resolution of inflammation associated with several pathologic conditions (5). Three $\mathrm{HO}$ isoforms (HO-1 to -3 ) have been identified so far (6); HO-1 represents the inducible enzyme (7). The major physiologic function 
of $\mathrm{HO}$ is the catalytic degradation of heme into biliverdin, carbon monoxide (CO), and free ferreous iron $\left(\mathrm{Fe}^{2+}\right)(8)$. Heme is released from numerous hemoproteins upon tissue injury and $\mathrm{HO}$ action is discussed to confer protective capacities, as the released heme moiety promotes free radical formation and lipid peroxidation that finally leads to tissue damage (9-11). In addition to heme (12), accordingly, expression of the inducible $\mathrm{HO}-1$ isoform is reported to be mediated by stress conditions such as heat shock (13), hyperoxia (14), hypoxia (15), endotoxin (16), inflammatory cytokines (17), and prostaglandins (18). Additionally, the inflammatory mediator nitric oxide (NO) has been recognized as one of the most potent inducers of $\mathrm{HO}-1$ gene expression for various cell types in vitro (19-23) as well as for different tissues in vivo (24-26).

NO has been identified as a central signaling molecule during the inflammatory phase of cutaneous wound repair. Notably, a tightly regulated, continuous release of NO derived from inducible NO synthase (iNOS) enzymatic activity during wound inflammation represents a crucial prerequisite for normal angiogenic and re-epithelialization processes; production of vascular endothelial growth factor (VEGF) $(27)$ and chemokines $(28,29)$ as well as the proliferation of wound margin keratinocytes (30) were strongly dependent on the availability of $\mathrm{NO}$ at the wound site.

To improve our understanding of wound inflammatory processes, especially in the context of a potential cross-talk between NO and HO expression, we investigated expressional regulation of the inducible HO-1 isoform during normal and impaired wound repair. Interestingly, only woundmacrophages strongly expressed HO-1 during healing. Notably, HO-1 expression in these macrophages was most likely independent of a regulatory control of NO at the wound site. Finally, we provide evidence that HO-l enzymatic activity might be implicated in the regulation of cytokine release from macrophages during the inflammatory phase of repair.

\section{Materials and Methods}

Inhibitor Treatment of Mice

Balb/c mice (Charles River, Sulzfeld, Germany) and C57BL/6J-ob/ob mice (Jackson Laboratory, Bar Harbor, ME, USA) were wounded as described below. During the wound healing period, female BALB/C mice ( 3 months old) were injected intraperitoneally twice a day at $7 \mathrm{AM}$ and $7 \mathrm{PM}$ with $2.5 \mathrm{mg} \mathrm{L-N}{ }^{6}$ (1-iminoethyl)lysine (L-NIL) in $0.5 \mathrm{ml}$ phosphatebuffered saline (PBS) per injection for 5 days. L-NIL represents a highly selective inhibitor of iNOS enzymatic activity (31). At this concentration, L-NIL almost completely blocked the in vivo enzymatic activity of iNOS in lymph nodes and peripheral skin lesions of Leishmania-infected mice. This inhibition of iNOs has been shown to be potent and presumably irreversible in vivo, and is not associated with weight loss and reduced water and food consumption of the treated animals $(32,33)$. Control mice were injected with PBS. L-NIL was from Alexis Corporation (Grünberg, Germany).

\section{Wounding and Preparation of Wound Tissues}

To examine gene expression during the wound healing process, six full-thickness wounds were created on each animal, and skin biopsy specimens from four animals were obtained 1, 3, 5, 7, and 13 days after injury. To investigate the effect of L-NIL on gene expression, wounds from four L-NIL-treated mice and four PBS-treated mice were obtained 1, 3 and 5 days after injury. Mice were anesthetized with a single intraperitoneal injection of Ketamin $(80 \mathrm{mg} / \mathrm{kg}$ body weight)/Xylazin ( $10 \mathrm{mg} / \mathrm{kg}$ body weight). The hair on the back of these mice were cut, and the back was subsequently wiped with $70 \%$ ethanol. Six full-thickness wounds (5 mm diameter, 3-4 mm apart) were made on the backs of these mice by excising the skin and the underlying panniculus carnosus. The wounds were allowed to dry to form a scab. An area 7-8 $\mathrm{mm}$ in diameter, which included the scab and the complete epithelial margins, was excised at each time point. As a control, a similar amount of skin was taken from the backs of four nonwounded mice. For every experimental time point, four wounds each from four animals $(n=16$ wounds) and the nonwounded back skin from four animals were combined, frozen immediately in liquid nitrogen, and stored at $-80^{\circ} \mathrm{C}$ until used for RNA isolation. All animal experiments were carried out according to the guidelines and with the permission from the local government of Hessen.

\section{Immunohistochemistry}

Mice were wounded as described. Animals were killed on day 5 after injury. Complete wounds were isolated from the middle of the back, bisected, and frozen in tissue freezing medium. Six-micrometer frozen serial sections were fixed with acetone and treated for $10 \mathrm{~min}$ at room temperature with $1 \%$ $\mathrm{H}_{2} \mathrm{O}_{2}$ in PBS to inactivate endogenous peroxidases. Directly neighbored serial sections were subsequently incubated for $60 \mathrm{~min}$ at room temperature with a polyclonal anti-serum raised against a polypeptide sequence of human HO-l (StressGen Biotechnologies, Victoria, Canada) or a monoclonal anti-serum raised against murine F4/80 antigen (Serotec, Eching, Germany) (1:50 diluted in PBS, $0.1 \%$ bovine serum albumin[BSA]). Both primary antibodies were detected using a biotinylated secondary antibody. The slides were subsequently stained with the avidin-biotin-peroxidase complex system from Santa Cruz (Heidelberg, Germany) using 3-3 diaminobenzidine-tetra-hydrochloride as a chromogenic substrate. After development, slides were rinsed with water, counterstained with hematoxylin, and mounted. 


\section{Cell Culture}

Murine RAW 264.7 macrophages were cultured in RPMI 1640 supplemented with 10\% endotoxinfree fetal calf serum (FCS). For the induction experiments, $1 \times 10^{7}$ cells were seeded and grown for $16 \mathrm{hr}$ to adhere the cells. Subsequently, fresh medium containing $10 \mu \mathrm{g} / \mathrm{ml}$ bacterial lipopolysaccharide (LPS, Escherischia coli serotype 0127:B8), $100 \mathrm{U} / \mathrm{ml}$ interferon- $\gamma($ IFN- $\gamma), 2$ mM N ${ }^{\mathrm{G}}$-monomethyl-l-arginine (L-NMMA), $500 \mu$ M S-nitroso-glutathione (GSNO), $350 \mu \mathrm{M}$ spermine-NONOate (SpNO), or $50 \mu \mathrm{M}$ tin protoporphyrin IX (SnPPIX) was added to the cells for different time periods. For the HO-l inhibition experiments using SnPPIX, cells were stimulated for $8 \mathrm{hr}$, and subsequently medium was replaced by fresh medium containing the same reagents. After an additional $2 \mathrm{hr}$, medium was harvested. This was done to enable the cells to produce NO that was shown to be crucial for $\mathrm{HO}-1$ induction. Aliquots of cells and cell culture supernatants were harvested before and at different time points after treatment with these agents and used for RNA and protein isolation, or enzyme-linked immunosorbent assays (ELISA). Each experiment was done in triplicate. FCS and RPMI were purchased from Life Technologies, Inc. (Eggenstein, Germany), L-NMMA and SnPPIX were from Alexis Inc., LPS was from Sigma Biochemicals (Deisenhofen, Germany), and IFN- $\gamma$ from Roche Biochemicals (Mannheim, Germany).

\section{RNA Isolation and RNase Protection Analysis}

RNA isolation was performed as described (34). Twenty micrograms of total RNA from wounded or nonwounded skin were used for RNase protection assays. Every experimental time point represents 16 wounds from four different animals that have been pooled for RNA isolation. RNase protection assays were carried out as described previously (27). Briefly, DNA probes were cloned into the transcription vector Bluescript II KS (+) (Stratagene, Heidelberg, Germany) and linearized. An antisense transcript was synthesized in vitro using T3 or T7 RNA polymerase and $\left[\alpha-{ }^{32} \mathrm{P}\right] \mathrm{UTP}(800$ $\mathrm{Ci} / \mathrm{mmol})$. RNA samples were hybridized at $42^{\circ} \mathrm{C}$ overnight with $100,000 \mathrm{cpm}$ of the labeled antisense transcript. Hybrids were digested with RNases A and Tl for $1 \mathrm{hr}$ at $30^{\circ} \mathrm{C}$. Under these conditions, every single mismatch is recognized by the RNases. Protected fragments were separated on $5 \%$ acrylamide/8M urea gels and analyzed using a PhosphoImager (Fuji, Straubenhardt, Germany). All protection assays were carried out with at least three different sets of RNA from independent wound healing or cell culture experiments. A 240bp fragment corresponding to nucleotides 544-784 of the murine HO-1 cDNA (35) and a 180-bp fragment corresponding to nucleotides 577-757 of the murine HO-2 cDNA (36) were used as templates. RNases A and Tl were from Roche Biochemicals.

\section{Preparation of Wound Lysates}

Biopsies of normal back skin and wounds $(n=8$ wounds) were taken and frozen immediately in liquid nitrogen. Total skin samples were homogenized in $2 \times$ homogenizing buffer $(1 \times$ homogenizing buffer: $20 \mathrm{mM}$ Tris/HCl, pH 8.0, $137 \mathrm{mM} \mathrm{NaCl}$, $10 \%$ glycerol, $5 \mathrm{mM}$ EDTA, $1 \mathrm{mM}$ phenylmethylsulfonyl fluoride, $15 \mu \mathrm{g} / \mathrm{ml}$ leupeptin). The tissue extract was cleared by centrifugation and the supernatant diluted 1:1 with water. The amount of protein in the cytoplasmic fractions of the lysates was determined using the Bio-Rad protein assay (Bradford method).

\section{Preparation of Cell Culture Lysates and Western Blot Analysis}

RAW 264.7 macrophages from the cell culture experiments were homogenized in lysis buffer $(1 \%$ Triton X-100, $20 \mathrm{mM}$ Tris/HCl, pH 8.0, $137 \mathrm{mM}$ $\mathrm{NaCl}, 10 \%$ glycerol, $5 \mathrm{mM}$ ethylendiamine tetraacetic acid, ImM phenylmethylsulfonyl fluoride, $1 \%$ aprotinin, $15 \mu \mathrm{g} / \mathrm{ml}$ leupeptin). The tissue extract was cleared by centrifugation. Fifty micrograms of total protein from skin and cellular lysates was separated using sodium dodecyl sulfate gel electrophoresis. After transfer to a PVDF membrane, HO-l protein was detected using the same HO-1 specific polyclonal antibody as described in Immunohistochemistry. A secondary antibody coupled to horseradish peroxidase and the ECL detection system were used to visualize HO-1 protein. Phenylmethylsulfonyl fluoride, aprotinin, and leupeptin were from Sigma, and the ECL detection system was obtained from Amersham (Freiburg, Germany).

\section{Enzyme-Linked Immunosorbent Assay}

Ten milliliters of macrophage (RAW 264.7)-conditioned cell culture supernatants from the individual experimental time points were pooled and cleared by centrifugation. One hundred microliters of the cell culture supernatants, or total protein (50 $\mu \mathrm{g}$ diluted in $1 \times$ homogenizing buffer to a final volume of $50 \mu \mathrm{l}$ ) from 13-day wounds isolated from control (Balb/c) or diabetic $(o b / o b)$ mice were subsequently analyzed for the presence of immunoreactive tumor necrosis factor- $\alpha$ (TNF- $\alpha)$, or interleukin- $1 \beta$ (IL- $1 \beta$ ) protein by ELISA using the Quantikine murine TNF- $\alpha$ or IL- $\beta$ kit (R\&D Systems, Wiesbaden, Germany) as described by the manufacturer.

\section{GSNO Synthesis}

GSNO was synthesized as described previously (37).

\section{Nitrite Determination}

Nitrite, a stable NO oxidation product, was determined using the Griess reaction. Cell-free culture supernatants were collected $(200 \mu \mathrm{l})$, adjusted to 
$4^{\circ} \mathrm{C}$, mixed with $20 \mu \mathrm{l}$ of sulfanilamide (dissolved in $1.2 \mathrm{M} \mathrm{HCl}$ ), and $20 \mu \mathrm{l}$ of $N$-naphtylethylenediamine dihydrochloride. After $5 \mathrm{~min}$ at room temperature, the absorbance was measured at $540 \mathrm{~nm}$ with a reference wavelength at $690 \mathrm{~nm}$. Sulfanilamide and $\mathrm{N}$-naphtylethylenediamine dihydrochloride were from Sigma Biochemicals.

\section{Statistical Analysis}

Data are shown as mean \pm SD. The data are presented as percent induction compared with the unstimulated control $(100 \%)$. Data were analyzed by unpaired Student $t$ test on raw data using Sigma Plot (Jandel Scientific, Erkrath, Germany).

\section{Results}

Wound Repair Is Characterized by a Strong

Increase in HO-1 Expression Levels

Because expression of $\mathrm{HO}-1$ is discussed as contributing to inflammatory processes associated with different pathologic conditions (5), we postulated a potential presence of $\mathrm{HO}-1$ also during the inflammatory phase of skin regeneration. To this end, we determined expression of $\mathrm{HO}-1$ at the mRNA and protein level during skin repair. As shown in Figure 1, nonwounded skin was characterized by a low level mRNA expression of $\mathrm{HO}-\mathrm{l}$, whereas $\mathrm{HO}-\mathrm{l}-$-specific protein was only hardly detectable using Western blot analysis ("ctrl skin"). More importantly, we observed a strong induction of HO-1 expression upon injury. Elevated levels of HO-1 mRNA and protein were observed to be transient, and could be detected from a few hours after injury (Fig. 1B) until day 7 postwounding (Fig. 1A). Thus, the time frame of HO- 1 expression was clearly restricted to the inflammatory phase of tissue repair. It is noteworthy that induction of HO-l at the mRNA level could be observed as early as $5 \mathrm{hr}$ after wounding, followed by detectable HO-1 protein after $16 \mathrm{hr}$ (Fig. 1B).

As a next step, we determined expression levels of the HO-2 isoform, which is well known to be constitutively expressed (7). Interestingly, we found HO-2 to be expressed in nonwounded skin (Fig. 2). Not unexpectedly, HO-2 mRNA expression was not altered upon injury and expression levels remained constant during the complete process of repair.

\section{HO-1 Expression During Repair Is Predominantly Restricted to Macrophages Located at the Wound Site}

As a next step, we determined the cellular sources of HO-l expression at the wound site. Interestingly, the expression kinetics of $\mathrm{HO}-1$ at the mRNA and also protein level clearly resembled the kinetics of monocyte/macrophage infiltration into the wound site $(4,29,38)$. For this reason, we speculated that HO-l expression might be related, at least partially, to the process of monocyte immigration into the wound bed. To assess this question,
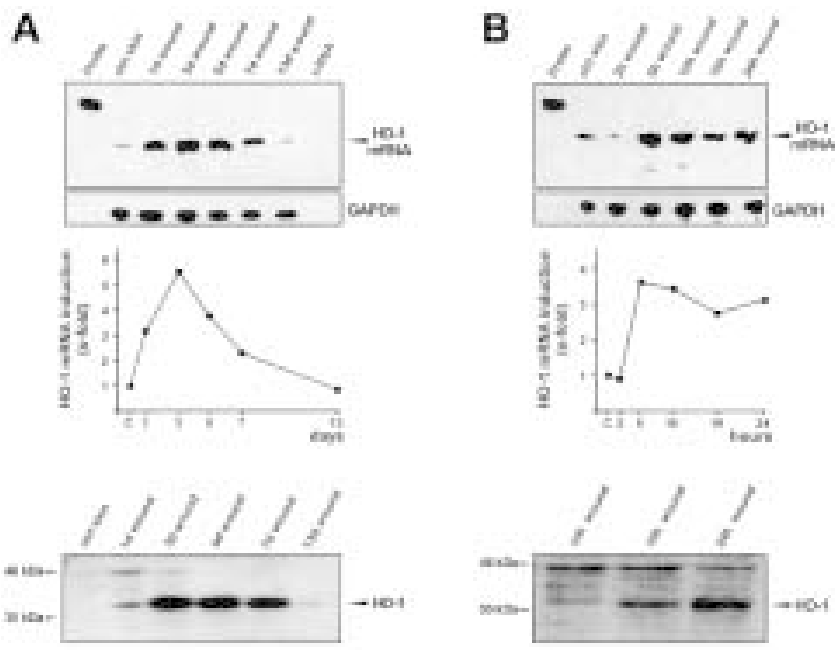

Fig. 1. Wound repair is characterized by strongly increased HO-1 mRNA and protein levels. The complete healing process (A), or the first $24 \mathrm{hr}$ of repair (B) were analyzed for HO-1 mRNA and protein expression. Total cellular RNA $(20 \mu \mathrm{g})$ from normal and wounded back skin of Balb/c mice was analyzed by RNase protection assay for expression of HO-l (A and B, upper panels). Sixteen wounds $(n=16)$ from the backs of four animals were excised for each experimental time point and used for RNA isolation. The time after injury is indicated at the top of each lane. "Control skin" refers to nonwounded skin. One thousand cpm of the hybridization probe were added to the lane labeled "probe." Expression of GAPDH mRNA is shown as a loading control. The degree of HO-l induction as assessed by PhosphoImager (Fuji) analysis of the radiolabeled gels is shown schematically in the middle panels. Note, that every experimental time point represents a total of 32 wounds from two independent animal experiments. Total protein $(50 \mu \mathrm{g})$ from lysates of nonwounded and wounded back skin (10 hr, $16 \mathrm{hr}$, and days 1, 3, 5, 7, and 13 after injury, indicated at the top of each lane) were analyzed by immunoblotting for the presence of HO-1-specific protein. Eight wounds from the backs of four animals were excised for each experimental time point and used for protein isolation. "Control skin" refers to nonwounded skin. $\mathrm{HO}-1$ protein is indicated by an arrow.

we performed an immunohistochemistry analysis from full-section excisional wounds that had been isolated 5 days postwounding. We have chosen to investigate $\mathrm{HO}-1$ expression at the 5 -day experimental time point because $\mathrm{HO}-1$ expression was strongly induced during this phase of the healing process (Fig. 1A). As shown in Figures 3A, 3C, and 3F, strong HO-1 immunopositive signals were nearly completely restricted to infiltrating macrophages, which were located deep in the developing granulation tissue. Identity of $\mathrm{HO}$-1-expressing cells within the granulation tissue as macrophages was confirmed using an additional immunohistologic analysis against the F4/80 antigen (Figs. 3B and 3D), which represents a $160-\mathrm{kDa}$ protein specific for murine macrophages (39). Thus, the immunohistochemistry data provide an explanation for the abovementioned expression kinetics of HO-l (Fig. 1A). Interestingly, we found a few keratinocytes of the wound margin hyperproliferative epithelia to express 


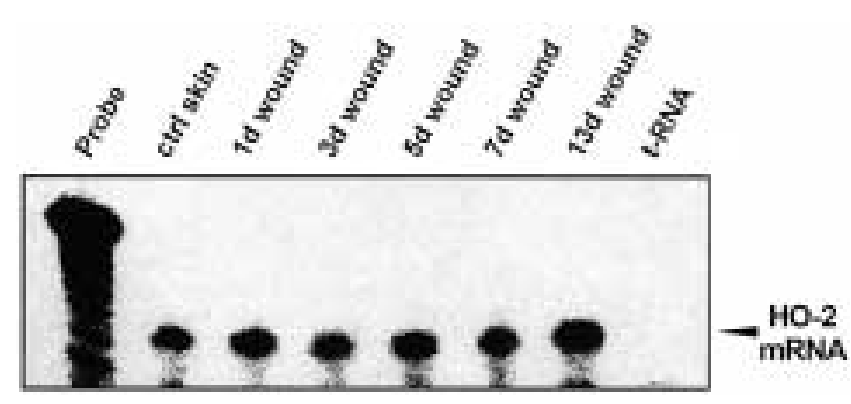

Fig. 2. HO-2 mRNA expression is not altered during skin repair. Total cellular RNA $(20 \mu \mathrm{g})$ from normal and wounded back skin of Balb/c mice was analyzed by RNase protection assay for expression of HO-2. Sixteen wounds from the backs of four animals were excised for each experimental time point and used for RNA isolation. The time after injury is indicated at the top of each lane. "Control skin" refers to nonwounded skin.

One representative experiment is shown.

HO-1 protein (Fig. 3E). These HO-1-expressing keratinocytes were located within the hyperproliferative epithelia of the wound margins that form the epithelial tongues covering the wound.
NO Is a Potent Inducer of HO-1 in the Murine RAW 264.7 Macrophage Cell Line in Vitro

Because we determined that wound macrophages were the predominant and major cellular source of HO-l at the wound site, we subsequently assessed potential regulators of $\mathrm{HO}-1$ expression using the murine RAW 264.7 macrophage cell line in vitro. We investigated the potency of the pro-inflammatory cytokines TNF- $\alpha$ and IL-1 $\beta$ to induce HO- 1 expression in the cells. However, both cytokines were not capable of inducing HO-1 in RAW 264.7 cells (data not shown). Thus, because NO has been reported to represent a potent mediator of HO-I expression (19), we treated the cells using different NO-donating agents. As shown in Figure 4A, exogenously added NO donors (500 $\mu \mathrm{M}$ GSNO, $350 \mu \mathrm{M}$ SpNO) strongly and rapidly induced $\mathrm{HO}-1$ protein expression. According to these results, we investigated the potency of endogenously produced NO to influence HO-l expression in the cells. To this end, we treated the cells using LPS $(10 \mu \mathrm{g} / \mathrm{ml})$ and IFN- $\gamma(100 \mathrm{U} / \mathrm{ml})$, as these conditions are well described as inducing iNOS in RAW 264.7 cells (40). Indeed, Figure 4B shows that
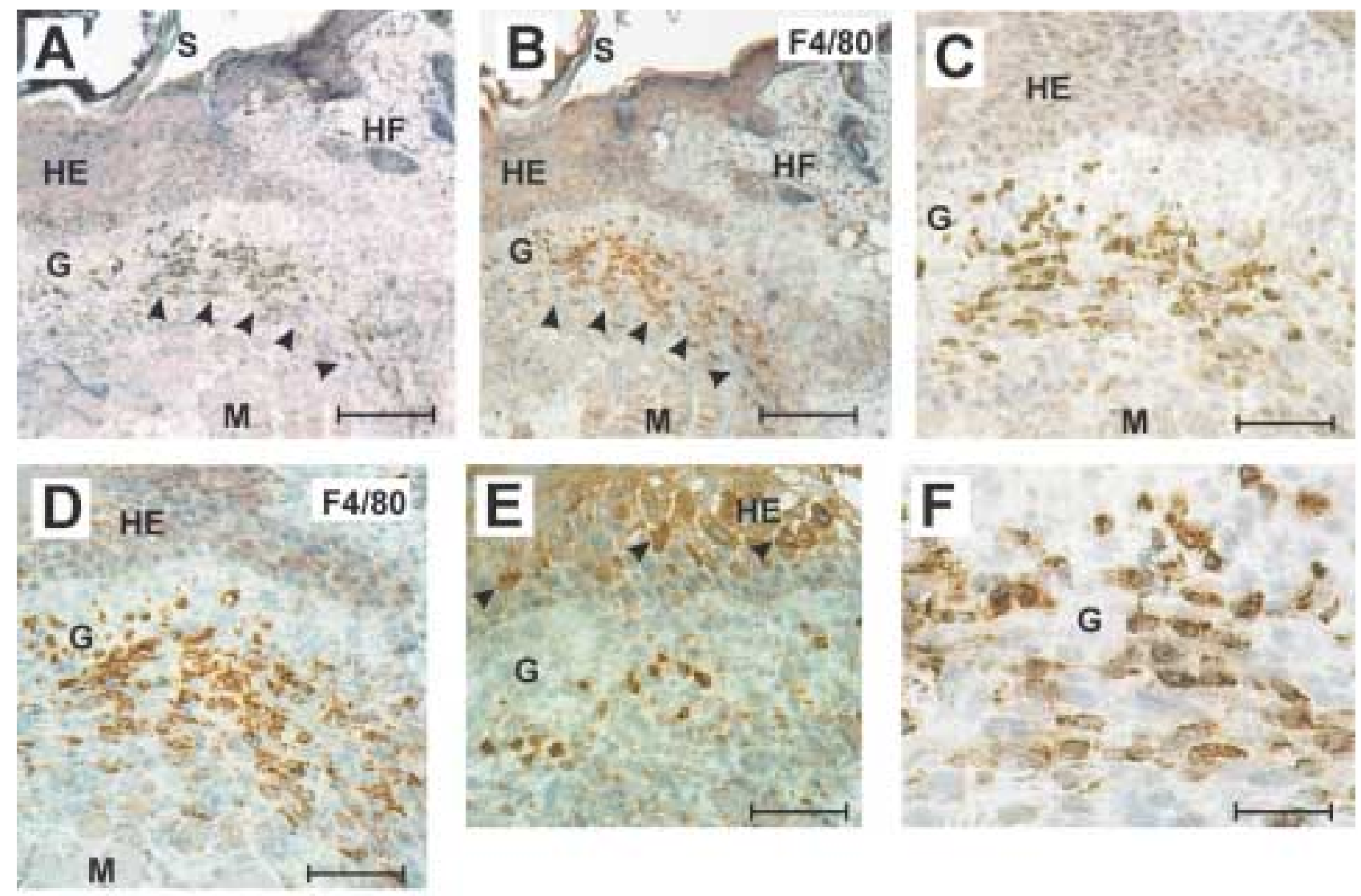

Fig. 3. HO-1 expression is predominantly restricted to wound macrophages. Frozen serial 6- $\mu$ m sections from 5-day mouse wounds were incubated with a polyclonal antibody directed against human HO-1 (A, C, E, F), or a monoclonal antibody directed against the murine macrophage-specific F4/80 antigen (B, D). Note that A and B, or C and D represent directly neighbored serial sections. All sections were stained with the avidin-biotin-peroxidase complex system using 3-3 diaminobenzidine-tetra-hydrochloride as a chromogenic substrate. Nuclei were counterstained with hematoxylin. Strongly immunopositive signals within the sections are indicated with arrows. Scale bars are $200 \mu \mathrm{m}$ for A and B, $100 \mu \mathrm{m}$ for C, D, E, and $50 \mu \mathrm{m}$ for F. G, granulation tissue; HE, hyperproliferative epithelium; HF, hair follicle; $M$, muscle; $S$, scab. 
A
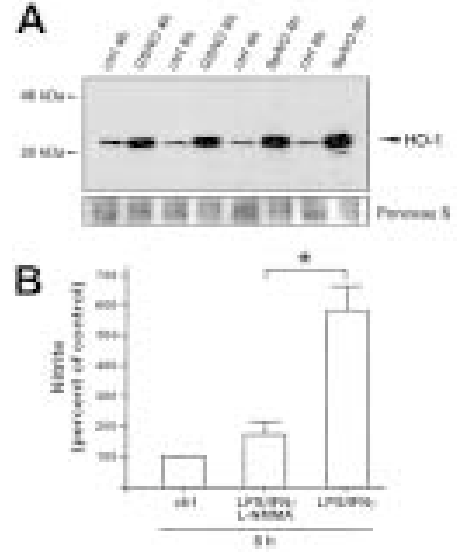

C
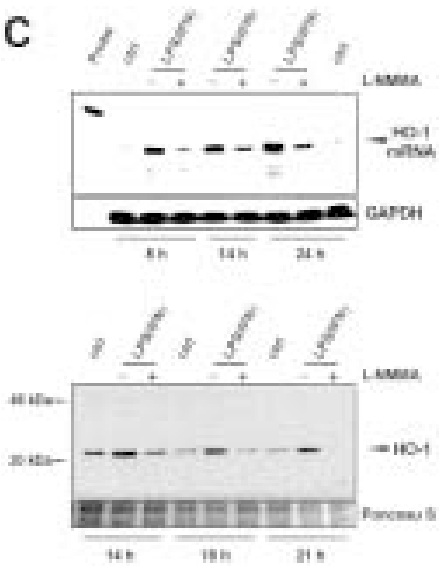

Fig. 4. NO is a potent inductor of HO-1 mRNA and protein expression in the RAW 264.7 macrophage cell line. (A) Adhered RAW 264.7 macrophages were treated with the NO-donating reagents GSNO $(500 \mu \mathrm{M})$, or SpNO $(350 \mu \mathrm{M})$ for 4 and $8 \mathrm{hr}$ as indicated. Total protein $(50 \mu \mathrm{g})$ of the cells was analyzed by immunoblotting for the presence of HO-1-specific protein. A Ponceau S staining of the same gel is shown as loading control. One representative experiment is shown. (B and C) RAW 264.7 cells were stimulated with LPS $(10 \mu \mathrm{g} / \mathrm{ml}) / \mathrm{IFN}-\gamma(100 \mathrm{U} / \mathrm{ml})$ in the presence or absence of L-NMMA ( $2 \mathrm{mM})$. NO-production of the cells after $8 \mathrm{hr}$ in the presence of these reagents was assessed by measuring nitrite accumulation in the cell culture supernatants as indicated (B). Data are expressed as percent of unstimulated control $\pm \mathrm{SD}(n=3) .{ }^{*} p<0.05$ compared with the conditions as indicated by the bracket. (C) Cells were treated as indicated. Twenty micrograms of total cellular RNA (C, upper panel), or $50 \mu \mathrm{g}$ of total protein lysate $(\mathbf{C}$, lower panel) were analyzed for the presence of HO-1 expression at indicated time points by RNase protection assay or Western blot analysis, respectively. $\mathrm{HO}-1$ specific signals were indicated by arrows. Expression of GAPDH mRNA (C, upper panel), or Ponceau S staining (C, lower panel) of the membrane, respectively, were shown as loading controls. macrophages clearly responded to an LPS/IFN- $\gamma$ stimulus; we could assess a strong accumulation of nitrite in the cell culture supernatants, that could be nearly completely attenuated by the NOS-inibitor $\mathrm{N}^{\mathrm{G}}$-monomethyl-l-arginine (L-NMMA, $2 \mathrm{mM}$ ). Induction of endogenous NO production by LPS/IFN- $\gamma$ was clearly associated with a strong increase in HO-1 mRNA and protein expression in the macrophages. More importantly, LPS/IFN- $\gamma$-induced HO- 1 was nearly completely dependent on the availability of endogenously produced NO because the presence of L-NMMA suppressed HO-1 protein expression to control levels (Fig. 4C). In summary, these in vitro experiments further strengthen the important role of NO for HO-1 expressional regulation.

\section{NO Does Not Modulate HO-1 Expression During Skin Repair in Vivo}

Recently, we reported the presence of iNOS during the inflammatory phase of skin repair (41). Moreover, we have established an animal model characterized by the specific inhibition of iNOS enzymatic activity at the wound site. Inhibition of iNOS during repair resulted in severely impaired epithelial regeneration processes $(27,30)$, but, most important for this study, infiltration of macrophages was clearly not impaired after L-NIL treatment of the mice (29). To assess the role of $\mathrm{NO}$ as an inductor of HO-1 in vivo, we used this NO-deficient animal model $(27,30)$ to determine $\mathrm{HO}-\mathrm{l}$ expression in the presence or absence of wound-derived NO production. It was surprising to us and, moreover, also in clear contrast to our in vitro findings (Fig. 4), that we could not observe any differences in HO-1 mRNA expression in normal compared to NO-deficient healing (Fig. 5). Thus, the role of $\mathrm{NO}$ as a potent mediator of $\mathrm{HO}-\mathrm{l}$ induction, obviously, has to be interpreted more carefully in the context of inflammatory conditions, which are associated with a "physiologic" process such as tissue regeneration.

\section{Induction of HO-1 Contributes to the Synthesis of Pro-Inflammatory Cytokines in RAW 264.7 Macrophages in Vitro}

Finally, we intended to reveal a possible function of macrophage-derived HO-1 for the wound healing process. Because $\mathrm{HO}-1$ expression is associated with the inflammatory phase of repair, and, moreover, nearly completely restricted to wound macrophages,

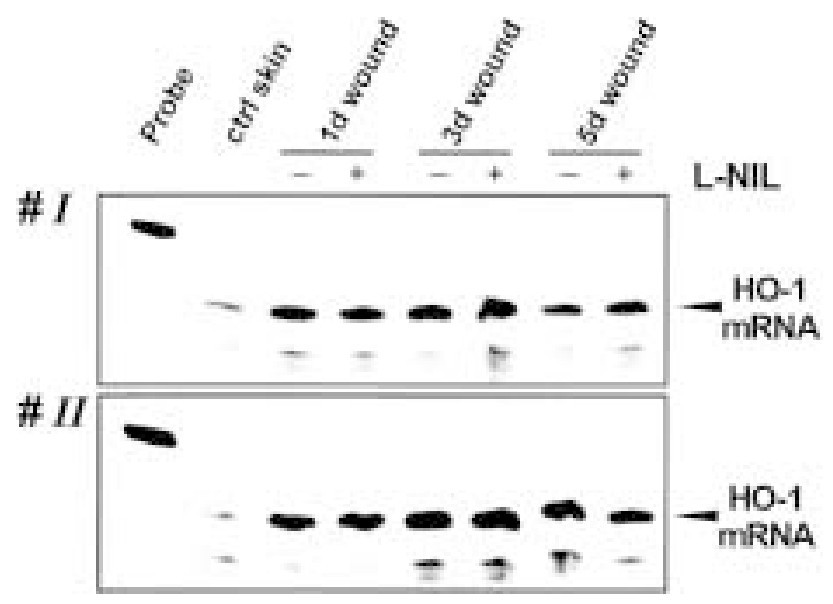

Fig. 5. NO does not influence HO-l expression during skin repair in vivo. Total cellular RNA $(15 \mu \mathrm{g})$ from nonwounded and wounded back skin of PBS $(-)$ and L-NIL (+) injected mice of two independent experimental series (\#I, \#II as indicated) was analyzed by RNase protection assay for the presence of HO-1 mRNA. Sixteen wounds from the backs of four animals were excised for each experimental time point and used for RNA isolation. The time after injury is indicated at the top of each lane. "Control skin" refers to nonwounded skin. One thousand cpm of the hybridization probe were added to the lane labeled "probe." 
A

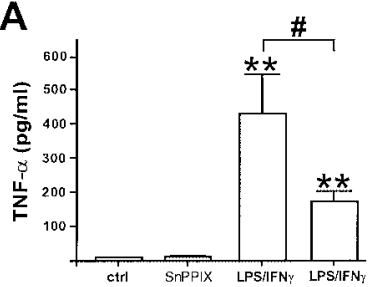

B

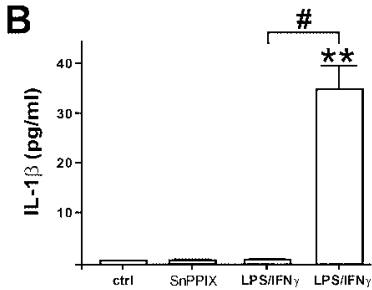

Fig. 6. HO-1 activity contributes to cytokine release in RAW 264.7 macrophages. RAW 264.7 macrophages were treated for $8 \mathrm{hr}$ with LPS $(10 \mu \mathrm{g} / \mathrm{ml}) / \mathrm{IFN}-\gamma(100 \mathrm{U} / \mathrm{ml})$ in the presence or absence of the HO-1 inhibitor SnPPIX $(50 \mu \mathrm{M})$. After $8 \mathrm{hr}$, medium was removed and fresh medium containing the same stimulants (LPS, IFN- $\gamma \pm$ SnPPIX) was added to the cells for additional 2 hr. Subsequently, after 2 hr of incubation, conditioned media were removed and analyzed by ELISA for the presence of TNF- $\alpha$ (A) or IL-1 $\beta$ (B). Data are expressed as mean concentration $\pm \mathrm{SD}(n=3) .{ }^{* *} p<0.01$ compared with control. ${ }^{*} p<0.05$ compared with the conditions as indicated by the brackets.

we hypothesized that HO-1 might contribute to macrophage-derived cytokine production. This might be true, because macrophages are well established as representing a major source of cytokines during repair. Additionally, previous reports have provided evidence for $\mathrm{HO}-1$ in the control of cytokine release from monocytic cells $(42,43)$. To assess this possibility, we stimulated RAW 264.7 macrophages using LPS/IFN- $\gamma$ to induce HO- 1 expression (see Figs. 4B and 4C) in the presence or absence of the HO-1 inhibitor SnPPIX. We observed a marked (about $60 \%$ ) reduction of TNF- $\alpha$ release from LPS/IFN- $\gamma$-activated RAW 264.7 macrophages that was paralleled by HO-l enzymatic inhibition (Fig. 6A). Interestingly and contrasting the situation observed for TNF- $\alpha$, the same HO-1 inhibitory conditions led to a strong increase in IL- $1 \beta$ protein released into the cell culture supernatants (Fig. 6B). Most remarkably, a LPS/ IFN- $\gamma$-induced HO- 1 most likely mediated a complete suppression of IL- $1 \beta$ release; inhibition of LPS/ IFN- $\gamma$-induced HO- 1 activity by SnPPIX resulted in a strong release of IL- $1 \beta$ from the cells (Fig 6B).

\section{Dysregulation of HO-1 Expression During Impaired Wound Repair Is Associated With Elevated Levels of Pro-Inflammatory Cytokines}

Finally, because our in vitro experiments using the macrophage cell line RAW 264.7 suggested a contribution of HO-1 enzymatic activity to the release of pro-inflammatory cytokines from the cells, we assessed a possible participation of this mechanism also for the in vivo situation during skin repair. To this end, we investigated a situation of severely impaired wound healing conditions which is well described for the genetically diabetic ob/ob mouse $(44,45)$. First, we determined HO- 1 expression at the protein level during the impaired healing process in these animals. As shown in Figure 7A, skin repair in
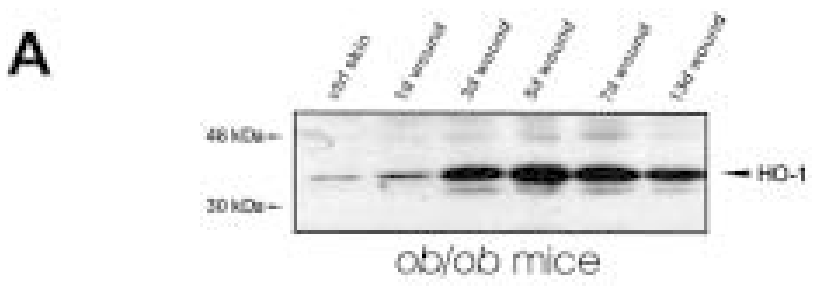

B
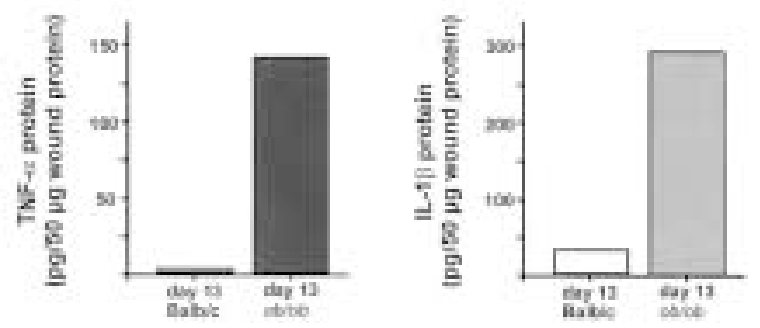

Fig. 7. Dysregulated HO-1 and cytokine expression during impaired repair. (A) Total protein $(50 \mu \mathrm{g})$ from lysates of nonwounded and wounded back skin (days 1, 3, 5, 7, and 13 after injury, as indicated at the top of each lane) isolated from diabetic $o b / o b$ mice was analyzed by immunoblotting for the presence of HO-1-specific protein. "Control skin" refers to nonwounded skin of $o b / o b$ mice. (B) Total protein $(50 \mu \mathrm{g})$ from lysates of 13-day wounds isolated from healthy control mice (Balb/c) and diabetic $o b / o b$ mice as indicated was analyzed by ELISA for the presence of TNF- $\alpha$ (left panel) or IL-1 $\beta$ (right panel) specific proteins. Six wounds from the backs of three animals were excised for each experimental time point shown in $\mathbf{A}$ and $\mathbf{B}$ and used for protein isolation.

diabetic $o b / o b$ mice was characterized by a strong increase in $\mathrm{HO}-1$ protein present at the wound site. By contrast to normal healing conditions, which were represented by a marked and clear down-regulation of HO-l protein at late stages of repair (see Fig. 1A, day 13), it is important to note that elevated levels of HO-1 protein were strongly associated with impaired skin repair at a late time point of healing in ob/ob mice (Fig. 7A, day 13). Thus, the observation of marked differences in $\mathrm{HO}-1$ protein expression at the wound site during late repair in healthy $(\mathrm{Balb} / \mathrm{c})$ and diabetic $(o b / o b)$ mice provides access to investigating a possible association between the presence of $\mathrm{HO}-1$ and expression of pro-inflammatory cytokines at the wound site. Interestingly, we observed a strong expression of TNF- $\alpha$ and IL- $1 \beta$ at day 13 postwounding in $o b / o b$ mice (Fig. 7B), which represents the experimental time point that was indeed characterized by elevated levels of HO-l (Fig. 7A). However, although the observed dysregulation for both $\mathrm{HO}-1$ and cytokine expression during delayed repair does not provide a final functional evidence, these data demonstrate a possible correlation between these systems as suggested by our in vitro experiments.

\section{Discussion}

Inflammation is a physiologic response of the skin to cope with tissue damage that is associated with injury. 
Inflammation is Janus -faced; it enables and crucially drives tissue repair by stimulation of resident cells to migrate and proliferate into the wound bed, but also severely disturbs wound healing processes when inflammation is prolonged (38). Thus, inflammation has to be tightly controlled to initiate a normal restoration of cutaneous tissue. Expression of HO has long been known to participate in inflammatory conditions. Interestingly, early in vivo studies in rats reported a protective function for $\mathrm{HO}$, because circulating hemoproteins resulted in kidney damage that is markedly reduced after hemoglobin-induced HO-l and ferritin expression (46). Because the heme moiety that is released from numerous hemoproteins under conditions of tissue damage promotes free radical formation and lipid peroxidation (9-11) and, thus, further contributes to cellular injury, detoxification of heme by catalytic degradation has to be regarded as one major function of HO enzymatic activity. Accordingly, expression of $\mathrm{HO}-1$, which represents the inducible $\mathrm{HO}$ isoform (7), can be activated by stimuli that are associated with inflammation such as proinflammatory cytokines (17), oxidative stress (47), or NO (19). In line, induction of the $\mathrm{HO}-1$ promoter has been shown for $\mathrm{NF} \kappa \mathrm{B}, \mathrm{AP}-1$ and AP-2, three transcription factors that are activated by free radicals (48).

Because the abovementioned stimuli represent major contributors to a "physiologic" inflammatory situation that is coupled with normal tissue regeneration processes, it was tempting to speculate that $\mathrm{HO}$, especially the HO- 1 isoform, might be involved in skin repair. Indeed, tissue repair was characterized by a rapid increase in HO-1 mRNA and protein levels. Nevertheless, our data provide evidence that the observed increase in $\mathrm{HO}-\mathrm{l}$ protein at the wound site is not a result of a de novo expression from the HO-l gene in resident cells located at the wound margins or in the wound bed. Immunohistochemistry clearly revealed infiltrating monocytic phagocytes as the predominant and major cellular source of HO-1 protein. This observation is in line with previous reports that have shown a restricted expression of $\mathrm{HO}-1$ in astrocytes and macrophages in a stab injury model of the brain cortex and, additionally, in a traumatized brain model in rats $(49,50)$. Furthermore, our immunohistochemistry data suggest that HO-1 protein is transferred into the wound by immigrating monocytes. This observation is further strengthened by two recent reports from our laboratory $(29,38)$, where we could demonstrate macrophage infiltration kinetics (as assessed by the macrophage-specific marker proteins F4/80 and lysozyme $M$ ) that are not distinguishable from HO-1 mRNA and protein levels (Fig. 1). Nevertheless, the infiltration of monocytes fails to explain the rapid expressional induction of $\mathrm{HO}-1$ at the mRNA level within hours after injury. Because heme represents a potent inducer of HO-l expression (12) and, furthermore, heme is released in large amounts during hemorrhage, it has to be discussed that heme participates, at least partially, in HO-1 gene expression in resident cells very early after wounding. Notably, polymorphonuclear neutrophils arrive within hours at the wound site (51). Because polymorphonuclear neutrophils have been reported to express $\mathrm{HO}-1$ in a model of acute inflammation in the rat (52), these immune cells might represent an additional cellular source of early HO-1 induction.

It is well established that NO potently drives expression of the inducible $\mathrm{HO}-\mathrm{l}$ isoform. This phenomenon seems to represent a common principle; NO-dependent expression of $\mathrm{HO}-1$ has been demonstrated from various cell types and tissues such as fibroblasts $(20)$, mesangial cells $(22,53)$, vascular smooth muscle cells (19), brain, spleen (25), solid tumors (24), and xenografts (26). Thus, induction of HO-1 in the murine RAW 264.7 macrophage cell line by exogenously added and also by endogenously produced NO further supports these reports. Moreover, NO-induced HO-l expression has been shown for primary liver macrophages (21). Because we had identified wound macrophages as the predominant source of HO-1 during repair, and $\mathrm{HO}-1$ expression being under regulatory control of $\mathrm{NO}$ in macrophages in vitro (21, this study), we hypothesized that inhibition of iNOS enzymatic activity during the inflammatory phase of healing might influence $\mathrm{HO}-1$ expression in wound macrophages. Previous studies from our laboratory have shown that inhibition of iNOS enzymatic activity by the specific iNOS inhibitor L-NIL abolished wound nitrite production $(27,30)$, and more importantly, severely interfered with epithelial repair processes such as production of the highly angiogenic VEGF (27), keratinocyte proliferation (30), or chemokine release $(28,29)$. Moreover, despite impaired epithelial repair (30), we have observed unaltered macrophage cell numbers at the wound site after inhibition of iNOS activity (29). Thus, alterations of HO- 1 expression levels after inhibitor treatment of mice would reflect the potency of NO to regulate $\mathrm{HO}-1$ expression in this in vivo situation rather than a reduction of immune cell numbers. Unexpectedly, HO-l levels remained unaltered. This observation suggests that, although NO is well established as an inducer of HO-l expression, this is not the case for the in vivo situation of cutaneous wound repair, for as yet unknown reasons. This observation implies that expression of $\mathrm{HO}-\mathrm{l}$ is already determined, at least, when extravasation of monocytes starts. In addition, the effect of $\mathrm{NO}$ on $\mathrm{HO}-1$ expression might be surpassed in the cells by more potent mediators that are present at the wound site.

Immunohistochemistry and also Western blot analyses revealed a strong presence of $\mathrm{HO}-1$ protein at the wound site. Thus, it is reasonable to propose the products of $\mathrm{HO}$ catalytic activity to be present in the developing granulation tissue: biliverdin, carbon monoxide (CO), and free ferrous iron $\left(\mathrm{Fe}^{2+}\right)$, which might participate in tissue inflammation. A recent 
study clearly indicated that $\mathrm{HO}-1$ expression has to be under a close regulatory control to enable its protective properties against cellular injury during inflammatory conditions. Fibroblasts were protected against hyperoxia by a low level expression of HO- 1 , whereas high levels of $\mathrm{HO}-1$ further contributed to cell injury by release of reactive iron (54). $\mathrm{Fe}^{2+}$ represents a powerful oxidant facilitating radical formation (55), but, by contrast, the same $\mathrm{Fe}^{2+}$ ion is capable of inducing ferritin, a protein that serves cytoprotective functions by sequestering iron (56).

$\mathrm{CO}$, as a gaseous messenger similar to NO, activates guanylate cyclase and interferes with signal transduction and gene expression processes (47, 57-59). Wound-derived NO drives a highly mitogenic response in wound margin keratinocytes (30) that is associated with an altered gene expression during repair (27-29). Therefore, wound keratinocytes might also be considered to be sensitive to woundderived CO. Accordingly, NO-induced HO-l expression and activity finally led to an marked increase in keratinocyte proliferation in vitro, which was completely abolished by simultaneous treatment of the cells using the HO-l inhibitor SnPPIX (23).

Finally, recent studies suggested an additional role for $\mathrm{HO}-1-$ derived $\mathrm{CO}$ in the synthesis of proinflammatory cytokines in macrophages. However, data obtained from primary macrophages and the macrophage cell line RAW $\mathbf{2 6 4 . 7}$ are partially contradictory. Whereas TNF- $\alpha$ release from re-oxygenated primary rat peritoneal macrophages was nullified by inhibition of HO-1 (42), Otterbein et al. (43) reported a strong attenuation of TNF- $\alpha$ production in HO-1 transfected or CO-treated RAW 264.7 macrophages. These differences may be due to cell-type specificities or the different stimuli used to activate the cells. Our data confirmed a contribution of HO-1 enzymatic activity in macrophage-derived cytokine release in RAW 264.7 cells. At this point, it has to be mentioned that SnPPIX has been reported to partially inhibit heme-dependent proteins not related to HO such as guanylate cyclase or NOS (60). By contrast, recent data implied that SnPPIX becomes a more competitive inhibitor when HO-1 levels are significantly increased (61). In line, HO-l was strongly increased in RAW 264.7 cells during our experimental conditions. Moreover, the attenuation of TNF- $\alpha$ release, which was contrasted by the simultaneous increase in IL- $1 \beta$ production in the same cells, provides strong evidence that the observed alterations in cytokine release were not a result of a general interference of SnPPIX with cytokine-releasing pathways in macrophages. However, and in line with data presented in this study, it becomes obvious that HO-l activity might be implicated in regulation of inflammatory processes by interference with cytokine-releasing mechanisms.

Nevertheless, such a hypothesis might be further strengthened by two additional observations. First, $\mathrm{HO}-1$ expression was not altered in NO-deficient wound healing (in this study). NO-deficient healing is well described to run into an impaired repair process $(30,62)$ that is definitely not associated with elevated expression levels of the pro-inflammatory cytokines TNF- $\alpha$ and IL-1 $\beta$ (28). Second, impaired repair coupled with a diabetic phenotype indeed resulted in elevated HO- 1 expression (this study) that was clearly associated with a dysregulated TNF- $\alpha$ and IL- $1 \beta$ expression. Obviously, it is tempting to argue that elevated levels of pro-inflammatory cytokines are not a common outcome of impaired repair in general, but must be coupled to distinct processes involved during formation of a nonhealing wound. Accordingly, such a process could be discussed to be represented by the presence of HO-l during tissue regeneration.

In summary, we have shown that $\mathrm{HO}-1$ is present during cutaneous healing, and is predominantly restricted to macrophages. In vitro studies indicated a potent regulatory role for NO in macrophagederived HO- 1 expression. However, this in vitro observation was in contrast to the in vivo situation of cutaneous tissue regeneration; NO failed to alter HO-1 levels at the wound site. Finally, our data suggest that HO-1 might function to control macrophagederived cytokine production in the developing granulation tissue.

\section{Acknowledgment}

We gratefully acknowledge Dr. Martin Kock for his help regarding the animal experiments. This work was supported by a grant of the Deutsche Forschungsgemeinschaft (SFB 553) and the Adolf Messer-Stiftung.

\section{References}

1. Martin P. (1997) Wound healing-aiming for perfect skin regeneration. Science 276: 75-81.

2. Clark RAF. (1996)Wound repair: overview and general considerations. In: Clark RAF, ed. The Molecular and Cellular Biology of Wound Repair. New York: Plenum, pp. 3-50.

3. Leibovich SJ, Ross R. (1975) The role of the macrophage in wound repair. A study with hydrocortisone and antimacrophage serum. Am. J. Pathol. 78: 71-100.

4. DiPietro LA. (1995) Wound healing: the role of the macrophage and other immune cells. Shock 4: 233-240.

5. Dong Z, Lavrovsky Y, Venkatachalam MA, Roy AK. (2000) Heme oxygenase-1 in tissue pathology: the Yin and Yang. Am. J. Pathol. 156: 1485-1488.

6. McCoubrey WK Jr, Huang TJ, Maines MD. (1997) Isolation and characterization of a cDNA from the rat brain that encodes hemoprotein heme oxygenase-3. Eur. J. Biochem. 247: 725-732.

7. Elbirt KK, Bonkovsky HL. (1999) Heme oxygenase: recent advances in understanding its regulation and role. Proc. Assoc. Am. Physicians 111: 438-447.

8. Maines MD. (1997) The heme oxygenase system: a regulator of second messenger gases. Annu. Rev. Pharmacol. Toxicol. 37: 517-554.

9. Balla J, Jacob HS, Balla G, Nath K, Eaton JW, Vercellotti GM. (1993) Endothelial-cell heme uptake from heme proteins: induction of sensitization and desensitization to oxidant damage. Proc. Natl. Acad. Sci. U.S.A. 90: 9285-9289. 
10. Nath KA, Grande JP, Croatt AJ, Likely S, Hebbel RP, Enright H. (1998) Intracellular targets in heme protein-induced renal injury. Kidney Int. 53: 100-111.

11. Abraham NG, Lavrovsky Y, Schwartzman ML, et al. (1995) Transfection of the human heme oxygenase gene into rabbit coronary microvessel endothelial cells: protective effect against heme and hemoglobin toxicity. Proc. Natl. Acad. Sci. U.S.A. 92: 6798-6802.

12. Alam J, Shibahara S, Smith A. (1989) Transcriptional activation of the heme oxygenase gene by heme and cadmium in mouse hepatoma cells. J. Biol. Chem. 264: 6371-6275.

13. Willis D, Moore AR, Frederick R, Willoughby DA. (1998) Heme oxygenase: a novel target for the modulation of the inflammatory response. Nat. Med. 2: 87-90.

14. Lee PJ, Alam J, Sylvester SL, Inamdar N, Otterbein L, Choi AM. (1996) Regulation of heme oxygenase-1 expression in vivo and in vitro in hyperoxic lung injury. Am. J. Respir. Cell Mol. Biol. 14: 556-568.

15. Maines MD, Mayer RD, Ewing JF, McCoubrey WK Jr. (1993) Induction of kidney heme oxygenase-1 (HSP32) mRNA and protein by ischemia/reperfusion: possible role of heme as both promotor of tissue damage and regulator of HSP32. J. Pharmacol. Exp. Ther. 264: 457-462.

16. Otterbein L, Sylvester SL, Choi AM. (1995) Hemoglobin provides protection against lethal endotoxemia in rats: the role of heme oxygenase-1. Am. J. Respir. Cell Mol. Biol. 13: 595-601.

17. Terry CM, Clikeman JA, Hoidal JR, Callahan KS. (1998) Effect of tumor necrosis factor-alpha and interleukin- 1 alpha on heme oxygenase-1 expression in human endothelial cells. Am. J. Physiol. 274: H883-H891.

18. Rossi A, Santoro MG. (1995) Induction by prostaglandin Al of heme oxygenase in myoblastic cells: an effect independent of expression of the $70 \mathrm{kDa}$ heat shock protein. Biochem. J. 308: $455-463$.

19. Hartsfield CL, Alam J, Cook JL, Choi AM. (1997) Regulation of heme oxygenase-1 gene expression in vascular smooth muscle cells by nitric oxide. Am. J. Physiol. 273: L980-L988.

20. Alcaraz MJ, Habib A, Lebret M, Creminon C, Levy-Toledano S, Maclouf J. (2000) Enhanced expression of haem oxygenase- 1 by nitric oxide and antiinflammatory drugs in NIH 3 T3 fibroblasts. Br. J. Pharmacol. 130: 57-64.

21. Immenschuh S, Tan M, Ramadori G. (1999) Nitric oxide mediates the lipopolysaccharide dependent upregulation of the heme oxygenase-1 gene expression in cultured rat Kupffer cells. J. Hepatol. 30: 61-69.

22. Datta PK, Lianos EA. (1999) Nitric oxide induces heme oxygenase-1 gene expression in mesangial cells. Kidney Int. 55: 1734-1739.

23. Clark JE, Green CJ, Motterlini R. (1997) Involvement of the heme oxygenase-carbon monoxide pathway in keratinocyte proliferation. Biochem. Biophys. Res. Commun. 241: 215-220.

24. Doi K, Akaike T, Fujii S, et al. (1999) Induction of haem oxygenase-1 nitric oxide and ischaemia in experimental solid tumours and implications for tumour growth. Br. J. Cancer 80: 1945-1954.

25. Willis D, Tomlinson A, Frederick R, Paul-Clark MJ, Willoughby DA. (1995) Modulation of heme oxygenase activity in rat brain and spleen by inhibitors and donors of nitric oxide. Biochem. Biophys. Res. Commun. 214: 1152-1156.

26. Soares MP, Lin Y, Anrather J, et al. (1998) Expression of heme oxygenase-1 can determine cardiac xenograft survival. Nat. Med. 4: 1073-1077.

27. Frank S, Stallmeyer B, Kämpfer H, Kolb N, Pfeilschifter J. (1999) Nitric oxide triggers enhanced induction of vascular endothelial growth factor expression in cultured keratinocytes (HaCaT) and during cutaneous wound repair. FASEB J. 13: 2002-2014.

28. Frank S, Kämpfer H, Wetzler C, Stallmeyer B, Pfeilschifter J. (2000) Large induction of the chemotactic cytokine RANTES during cutaneous wound repair: a regulatory role for nitric oxide in keratinocyte-derived RANTES expression. Biochem. J. 347: $265-273$.
29. Wetzler C, Kämpfer H, Pfeilschifter J, Frank S. (2000) Keratinocyte-derived chemotactic cytokines: expressional modulation by nitric oxide in vitro and during cutaneous wound repair in vivo. Biochem. Biophys. Res. Commun. 274: 689- 696.

30. Stallmeyer B, Kämpfer H, Kolb N, Pfeilschifter J, Frank S. (1999) The function of nitric oxide in wound repair: inhibition of inducible nitric oxide-synthase severely impairs wound reepithelialization. J. Invest. Dermatol. 113: 1090-1098.

31. Moore WM, Webber RK, Jerome GM, Tjoeng FS, Misko TP, Currie MG. (1994) L- $\mathrm{N}^{6}$-(1-iminoethyl)lysine: a selective inhibitor of inducible nitric oxide synthase. J. Med. Chem. 37: $3886-3888$.

32. Stenger S, Thüring H, Röllinghoff $M$, Manning $P$, Bogdan C. (1995) L- $\mathrm{N}^{6}$-(1-iminoethyl)-lysine potently inhibits inducible nitric oxide synthase and is superior to $\mathrm{N}^{\mathrm{G}}$-monomethylarginine in vitro and in vivo. Eur. J. Pharmacol. 294: 703-712.

33. Diefenbach A, Schindler H, Donhauser N, et al. (1998) Type 1 interferon (IFNalpha/beta) and type 2 nitric oxide synthase regulate the innate immune response to a protozoan parasite. Immunity 8: 77-87.

34. Chomczynski P, Sacchi N. (1987) Single-step method of RNA isolation by acid guanidinium thiocyanate-phenol-chloroform extraction. Anal. Biochem. 162: 156-159.

35. Alam J, Cai J, Smith A. (1994) Isolation and characterization of the mouse heme oxygenase-1 gene. Distal 5' sequences are required for induction by heme or heavy metals. J. Biol. Chem. 269: 1001-1009.

36. Gibbs L, Willis D, Morgan MJ. (1998) The identification and expression of heme oxygenase- 2 alternative transcripts in the mouse. Gene 221: 171-177.

37. Hart TW. (1985) Some observations concerning the S-nitroso and S-phenylsulphonyl derivatives of L-cysteine and glutathione. Tetrahedron Lett. 26: 2013-2016.

38. Wetzler C, Kämpfer H, Stallmeyer B, Pfeilschifter J, Frank S. (2000) Large and sustained induction of chemokines during impaired wound healing in the genetically diabetic mouse: prolonged persistence of neutrophils and macrophages during the late phase of repair. J. Invest. Dermatol. 115: 245-253.

39. Austyn JM, Gordon S. (1981) F4/80, a monoclonal antibody directed specifically against the mouse macrophage. Eur. J. Immunol. 11: 805-815.

40. Messmer UK, Ankarcrona M, Nicotera P, Brüne B. (1994) p53 expression in nitric oxide-induced apoptosis. FEBS Lett. 355: 23-26.

41. Frank S, Madlener M, Pfeilschifter J, Werner S. (1998) Induction of inducible nitric oxide synthase and its corresponding tetrahydrobiopterin-cofactor-synthesizing enzyme GTPcyclohydrolase I during cutaneous wound repair. J. Invest. Dermatol. 111: 1058-1064.

42. Tamion F, Richard V, Lyoumi S, et al. (1998) Induction of haem oxygenase contributes to the synthesis of proinflammatory cytokines in re-oxygenated rat macrophages: role of cGMP. Cytokine 11: 326-333.

43. Otterbein LE, Bach FH, Alam J, et al. (2000) Carbon monoxide has anti-inflammatory effects involving the mitogenactivated protein kinase pathway. Nat. Med. 6: 422-428.

44. Ring BD, Scully S, Davis CR, Baker MB, Cullen MJ, Pelleymounter MA, Danilenko DM. (2000) Systemically and topically administered leptin both accelerate wound healing in diabetic ob/ob mice. Endocrinology 141: 446-449.

45. Frank S, Stallmeyer B, Kämpfer H, Kolb N, Pfeilschifter J. (2000) Leptin enhances wound re-epithelialization and constitutes a direct function of leptin in skin repair. J. Clin. Invest. 106: $501-509$.

46. Nath KA, Balla G, Vercellotti GM, Balla J, Jacob HS, Levitt MD, Rosenberg ME. (1992) Induction of heme oxygenase is a rapid, protective response in rhabdomyolysis in the rat. J. Clin. Invest. 90: 267-270.

47. Morita T, Perella MA, Lee ME, Kourembanas S. (1995) Smooth muscle cell-derived carbon monoxide is a regulator of vascular cGMP. Proc. Natl. Acad. Sci. U.S.A. 92: 1474-1479.

48. Lavrovsky Y, Schwartzman ML, Levere RD, Kappas A, Abraham NG. (1994) Identification of binding sites for 
transcription factors NF-kappa B and AP-2 in the promoter region of the human heme oxygenase 1 gene. Proc. Natl. Acad. Sci. U.S.A. 91: 5987-5991.

49. Dwyer BE, Nishimura RN, Lu SY, Alcaraz A. (1996) Transient induction of heme oxygenase after cortical stab wound injury. Brain Res. Mol. Brain Res. 38: 251-259.

50. Fukuda K, Richmon JD, Sato M, Sharp FR, Panter SS, Noble LJ. (1996) Induction of heme oxygenase-1 (HO-1) in glia after traumatic brain injury. Brain Res. 736: 68-75.

51. Kämpfer H, Mühl H, Manderscheid M, Kalina U, Kauschat D, Pfeilschifter J, Frank S. (2000) Regulation of IL-18 in keratinocytes (HaCaT): implications for early wound healing. Eur. Cytokine Netw. 11: 626-633.

52. Willis D, Moore AR, Willoughby DA. (2000) Heme oxygenase isoform expression in cellular and antibody-mediated models of acute inflammation in the rat. J. Pathol. 190: 627-634.

53. Sandau K, Pfeilschifter J, Brüne B. (1998) Nitrosative and oxidative stress induced heme oxygenase- 1 accumulation in rat mesangial cells. Eur. J. Pharmacol. 342: 77-84.

54. Suttner DM, Dennery PA. (1999) Reversal of HO- 1 related cytoprotection with increased expression is due to reactive iron. FASEB J. 13: 1800-1809.

55. Fridovich I. (1997) Superoxide anion radical (O2.-), superoxide dismutases, and related matters. J. Biol. Chem. 272: 18515- 18517.
56. Balla G, Jacob HS, Balla J, et al. (1992) Ferritin: a cytoprotective antioxidant strategem of endothelium. J. Biol. Chem. 267: 18148-18153.

57. Ramos KS, Lin H, McGrath JJ. (1989) Modulation of cyclic guanosine monophosphate levels in cultured aortic smooth muscle cells by carbon monoxide. Biochem. Pharmacol. 38: $1368-1370$

58. Verma A, Hirsch DJ, Glatt CE, Ronnett GV, Snyder SH. (1993) Carbon monoxide: a putative neural messenger. Science 259: 381-384.

59. Zhuo M, Small SA, Kandel ER, Hawkins RD. (1993) Nitric oxide and carbon monoxide produce activity-dependent long-term synaptic enhancement in hippocampus. Science 260: 1946-1950.

60. Grundemar L, Ny L. (1997) Pitfalls using metalloporphyrins in carbon monoxide research. Trends Pharmacol. Sci. 18: 193- 195.

61. Sammut IA, Foresti R, Clark JE, et al. (1998) Carbon monoxide is a major contributor to the regulation of vascular tone in aortas expressing high levels of haeme oxygenase-1. Br. J. Pharmacol. 125: 1437-1444.

62. Yamasaki K, Edington HD, McClosky C, et al. (1998) Reversal of impaired wound repair in iNOS-deficient mice by topical adenoviral-mediated iNOS gene transfer. J. Clin. Invest 101: 967-971. 